\title{
Mesenteric Embolization: Is It Safe in Patients With Acute Lower Gastrointestinal Hemorrhage?
}

\author{
Dong Won Lee, Seon Hahn Kim \\ Division of Colorectal Surgery, Department of Surgery, Korea University Anam Hospital, Korea University College of Medicine, Seoul, Korea
}

See Article on Page 205-208

An acute lower gastrointestinal hemorrhage is a common clinical problem for which various diagnosis and treatment methods have been studied. Flexible sigmoidoscopy, colonoscopy, angiography, radionuclide scintigraphy and multidetector row computed tomography have been used for the diagnosis [1], and colonoscopy maybe said to be the most convenient and effective preliminary method for the diagnosis of critical lower gastrointestinal (GI) hemorrhage. However, mesenteric angiography is effective when the bleeding focus cannot be diagnosed with colonoscopy. The treatments include embolization, vasopressin infusion and surgery. This article [2] is a retrospective study on 27 patients treated with mesenteric embolization for acute lower GI hemorrhages with various etiologies. Even though the number of patients was not large because not many centers have adequate environment/ facility/resources to actively perform this procedure in an emergency setting, this research still seems to be worthy of interests. The study reports that the success rate for mesenteric embolization is $87.1 \%$ and that the half of the initially failed cases shows successful re-embolization. The result is excellent compared to the $48 \%$ diagnosis rate reported by Gillespie et al. [3], as well as the $45 \%$ embolization and the $76 \%$ treatment success rates. Despite its not being mentioned in the paper, emergency capsule endoscopy for acute obscure-overt gastrointestinal bleeding (OOGIB) is an interesting issue. Leung et al. [4] reported that the method showed a much higher diagnosis rate for acute OOGIB than angiography did $(53.3 \%$ vs. $20.0 \%, P=0.016)$. The risk of rehemorrhage was lower than it was in the angiography group during the observation

Correspondence to: Seon Hahn Kim, M.D.

Department of Surgery, Korea University Anam Hospital, Korea University

College of Medicine, 73 Inchon-ro, Seongbuk-gu, Seoul 136-705, Korea

Tel: +82-2-920-6644, Fax: +82-2-928-1631

E-mail:drkimsh@korea.ac.kr

(c) 2013 The Korean Society of Coloproctology

This is an open-access article distributed under the terms of the Creative Commons Attribution NonCommercial License (http://creativecommons.org/licenses/by-nc/3.0) which permits unrestricted noncommercial use, distribution, and reproduction in any medium, provided the original work is properly cited. period of 48.5 months $(16.7 \%$ vs. $33.3 \%, \mathrm{P}=0.10)$. More prospective studies on the role of the emergency capsule endoscopy seem to be necessary.

\section{REFERENCES}

1. Lhewa DY, Strate LL. Pros and cons of colonoscopy in management of acute lower gastrointestinal bleeding. World J Gastroenterol 2012;18:1185-90.

2. Tan KK, Strong DH, Shore T, Ahmad MR, Waugh R, Young CJ. The safety and efficacy of mesenteric embolization in the management of acute lower gastrointestinal haemorrhage. Ann Coloproctol 2013;29:205-8.

3. Gillespie CJ, Sutherland AD, Mossop PJ, Woods RJ, Keck JO, Heriot AG. Mesenteric embolization for lower gastrointestinal bleeding. Dis Colon Rectum 2010;53:1258-64.

4. Leung WK, Ho SS, Suen BY, Lai LH, Yu S, Ng EK, et al. Capsule endoscopy or angiography in patients with acute overt obscure gastrointestinal bleeding: a prospective randomized study with long-term follow-up. Am J Gastroenterol 2012;107:1370-6. 